\title{
The Pharmacokinetic Plasma Profile of Mitomycin C, Measured After Sequential Intermittent Intravenous Administration*
}

\author{
J. LANKELMA, $†$ M. STUURMAN, J. VAN HOOGENHUIJZE, A. VAN BOCHOVE, J.B. VERMORKEN, J. \\ VERWEIJ and H.M. PINEDO \\ Department of Oncology, Free University Hospital, De Boelelaan 1117, 1007 MB Amsterdam, The Netherlands
}

\begin{abstract}
The pharmacokinetic plasma profile of mitomycin $C(M M C)$ was studied during sequential courses in man. $M M C$ was given repeatedly as i.v. bolus injections at fixed dose levels to the same patient either as a single agent or as part of different combination chemotherapy regimens. Large interindividual variations between the various pharmacokinetic parameters were observed. Statistical analysis showed no significant differences between average pharmacokinetic parameters when comparing the first and the second $M M C$ injection, except for the total body clearance $\left(\mathrm{Cl}_{\text {tot }}\right)$. The $\mathrm{Cl}_{\text {tot }}$ was higher for the second injection when compared to the first injection in a group of patients who received $M M C$ as a single agent (10 patients). For a group of patients receiving $M M C$ as part of a combination therapy the average values of $\mathrm{Cl}_{\text {tot }}$ of the first when compared to the second injection were not statistically different (nine patients). This observation could not be correlated with clinical observations on toxicities.
\end{abstract}

\section{INTRODUCTION}

Mrtomycin C (MMC) is a frequently used antineoplastic agent in the treatment of several malignancies (for recent reviews see [1]). However, its widespread use is often limited by the frequent occurrence of, sometimes severe, toxicities during repeated injections of MMC. Several studies have been reported now on the pharmacokinetic behaviour of MMC [2-7]. In previous studies, a microbiologic assay was used for the determination of MMC in plasma and urine [2]. Because of the insensitivity and lack of selectivity of the latter method, especially in detecting $\mathrm{MMC}$ in the presence of other cytostatic agents, a high performance liquid chromatographic (HPLC) method was developed with a detection limit as low as $1 \mathrm{ng} / \mathrm{ml}$ [8]. The pharmacokinetic profile of MMC could best be described with a linear two-compartment model and the drug showed a non-dose dependent linear behaviour [3, 4]. Metabolism in the liver is supposed to be the major mechanism of elimination of MMC from the plasma [9]. No relation between pharmacokinetic data and toxicity has been established. The most significant

\section{Accepted 6 August 1987}

*This study was supported by the Netherlands Cancer Foundation (grant No. KWF THT 84-1) and by Kyowa Hakko Kogyo Co. (Tokyo, Japan).

†Author to whom correspondence should be addressed. and frequent toxicity of MMC in man is delayed myelosuppression, which appears to be directly related to the schedule and the total dose [10].

Other reported side-effects include usually mild and infrequent anorexia, nausea and vomiting, and diarrhoea. Alopecia, stomatitis and rashes occur infrequently. More serious and sometimes lethal side-effects have recently been reported to be pulmonary fibrosis, haemolytic uraemic syndrome and cardiac failure [11-17]. No data are available on the possible changes in the pharmacokinetics of $\mathrm{MMC}$, induced by repeated intermittent administration and the occurrence of myelosuppression. The aim of the present study was to investigate whether intrapatient variations occur in the pharmacokinetics of MMC, when the drug is repeatedly given as i.v. bolus injections, at fixed doses and whether these might be related to the occurrence and extent of cumulative toxicities.

\section{MATERIALS AND METHODS}

Mitomycin C was obtained from Kyowa Hakko Kogyo Co. (Tokyo, Japan). All chemicals mentioned were of analytical reagent grade. Nineteen patients were included in this study, of which 10 received $\mathrm{MMC}$ as a single agent (group 1 ) at a dose range of $9-15 \mathrm{mg} / \mathrm{m}^{2}$, while nine patients were treated with MMC at dose ranges of $5-10 \mathrm{mg} /$ 
$\mathrm{m}^{2}$ as part of different combination chemotherapy regimens (group 2). In multiple drug administration, MMC was the last drug administered. MMC was administered as an i.v. bolus injection (injection time 1-3 min at 6-week intervals). At least two pharmacokinetic curves were obtained from each patient. From seven patients at least three curves were available. Before treatment all patients were studied for complete blood counts, renal function, liver function and urinalysis. Blood samples were collected from the arm, opposite to the injection site through a cannula inserted into a vein, prior to MMC infusion, at 0, 2, 4, 10, 20, 30, 60, 120, 180, 240 and $300 \mathrm{~min}$ (or as close as possible) after injection in heparinized tubes.

Samples were icc-cooled. After centrifuging the plasma was separated and stored at $-25^{\circ} \mathrm{C}$. Urinc was collected every hour for $3 \mathrm{~h}$ and stored at $-25^{\circ} \mathrm{C}$. Analysis of plasma was performed within 3 weeks, whereas urine was analysed within 2 wecks.

\section{HPLC method}

For analysis we used the assay described by Den Hartigh el al. [8]. Plasma and urine were extracted by liquid-liquid extraction (chloroform/isopropyl alcohol, 1:1, w/w). One millilitre of extraction solvent was added to $100 \mu \mathrm{l}$ plasma. The chromatographic system consisted of a $\mu$ Bondapack C18 RP column, a Waters model 440 dual wavelength detector and a Waters Wisp 710 automatic injector. A methanol/0.01 $\mathrm{M}$ phosphate buffer $(\mathrm{pH}=6.0$, $3: 7, \mathrm{w} / \mathrm{w})$ was used as the eluent. Detection was performed at $365 \mathrm{~nm}$, with Porfiromycin as internal standard (concentration $600 \mathrm{ng} / \mathrm{ml}$ ). The limit of quantitation was $1 \mathrm{ng}$ per $\mathrm{ml}$ plasma, collecting $1 \mathrm{ml}$ samples. The recovery from plasma was $\geqslant 80 \%$, measured over a concentration range of $5-2000 \mathrm{ng} / \mathrm{ml}$. The precision of the method was $\leqslant 5 \%$.

\section{Pharmacokinetic calculations}

For pharmacokinetic data analysis the same methods have been used as those reported beforc [4]. For MMC an open two-compartment model was assumed and the terminal half-life time $\left(l_{1 / 2}\right)$ was obtained from a least squares regression analysis of the points belonging to the second phase $(t \geqslant 60 \mathrm{~min})$. The area under the plasma concentration vs. time curve (AUC) was determined with the trapezoidal rule till the last time point and the total body clearance $\left(\mathrm{Cl}_{\mathrm{tot}}\right)$ was obtained by dividing the dose by the AUC. It was reported that using this procedure the obtained parameters did compare well with those obtained by using a non-linear curve fitting program [18]. The distribution volume $V_{\mathrm{d}}$ was calculated from $V_{\mathrm{d}}=\iota_{1 / 2} \cdot \mathrm{Cl}_{\text {tot }} / 0.693$. An alternative approach based on system dynamics to calculate the model independent parameter mean residence time (MRT) was followed according to Ref. [18]. The renal clcarance ( $\left(I_{1, \ldots 1}\right)$ wats obtained by dividing the total renal excretion by the . ILC:

\section{RESULTS AND DISCUSSION}

In total 19 patients have been included in the study, among which nine males (median age 47, range 42-86) and 10 females (median age 44, range 27-71). The diagnosis was breast cancer [7], prostate cancer [3], cervical cancer [1], adenocarcinoma of unknown origin [4], cholangio carcinoma [1], stomach cancer [2] and pancreatic cancer [1].

From most of the patients two curves were obtained. The most important pharmacokinetic parameters for both groups are listed in Tables 1 and 2. Most of the patients did not show highly different curves after repeated administration of the drug and had similar plasma concentration-time curves as shown in Fig. 1. The mean values of the half-life time of the elimination phase $\left(t_{1 / 2}\right)$, distribution volume $\left(V_{\mathrm{d}}\right)$, total body clearance $\left(\mathrm{Cl}_{\text {tot }}\right)$, renal clearance $\left(\mathrm{Cl}_{\text {ren }}\right)$ and mean residence time (MRT) values corresponded with previous reports $[4,7,9]$. The cumulative urinary excretion per cycle ranged from 0.2 to $22 \%$ for the single agent group and from 2 to $20 \%$ for the combination group. Variations in the duration of injection led to a missed peak-plasma concentration in some cases.

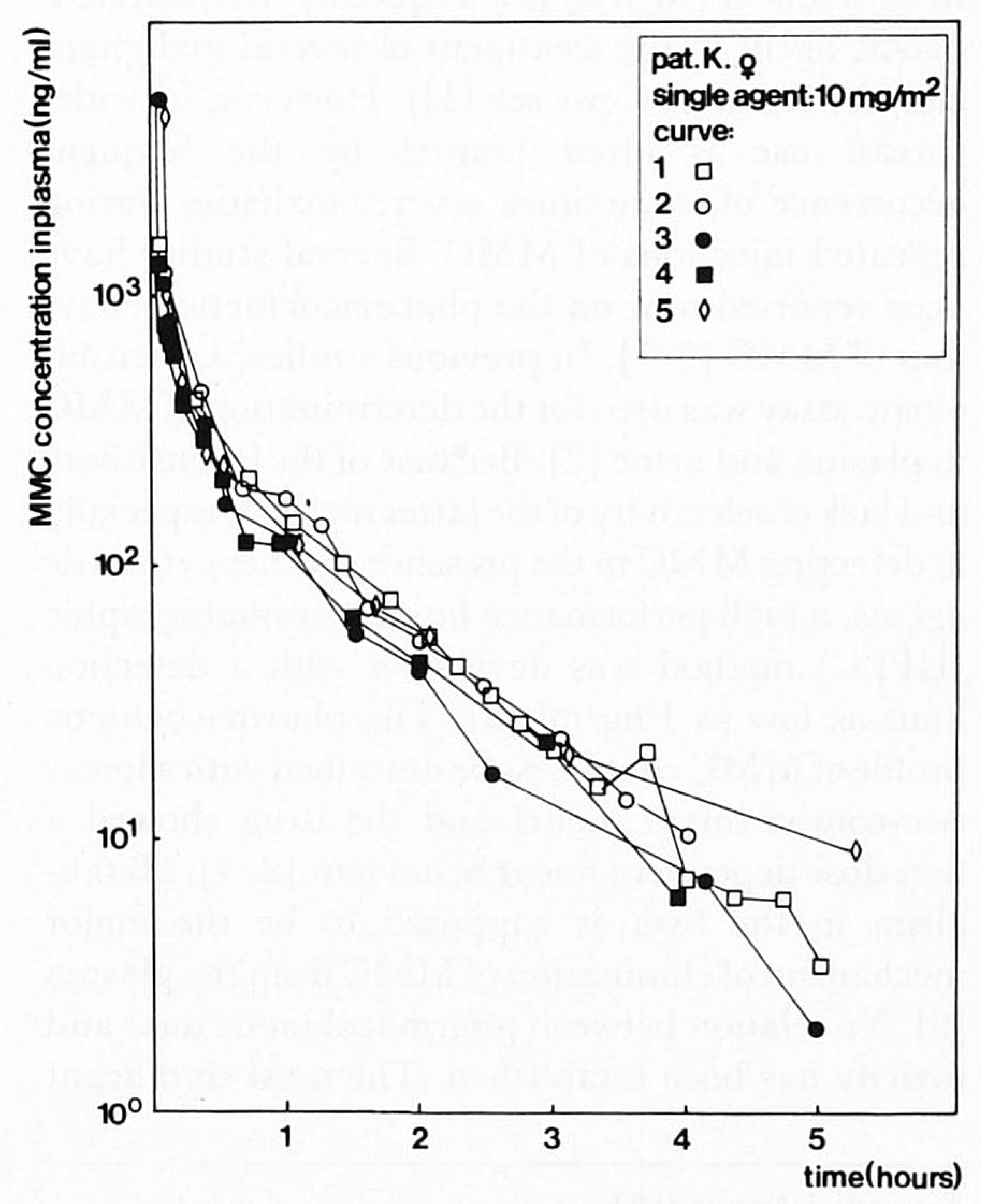

Fig. 1. Plasma concentration-time curve of $M M C$ of patient $K$ who received $M M C$ as a single agent at a dose of $10 \mathrm{mg} / \mathrm{m}^{2}$. No differences between the five curves were observed. 
Table 1. Pharmacokinetic parameters of patients receiving single agent $M M C^{*}$

\begin{tabular}{|c|c|c|c|c|c|c|c|c|c|}
\hline Patient & $\begin{array}{l}\text { Curve } \\
\text { No. }\end{array}$ & $\begin{array}{l}\text { Dose } \\
\left(\mathrm{mg} / \mathrm{m}^{2}\right)\end{array}$ & $\frac{t_{1 / 2}}{(\min )}$ & $\begin{array}{l}\text { AUC } \\
(\mu g \cdot h / l)\end{array}$ & $\begin{array}{l}V_{\mathrm{d}} \\
\left(1 / \mathrm{m}^{2}\right)\end{array}$ & $\begin{array}{l}\mathrm{Cl}_{t w t} \\
\left(\mathrm{l} / \mathrm{h} \cdot \mathrm{m}^{2}\right)\end{array}$ & $\begin{array}{l}\text { MRT } \\
(\min )\end{array}$ & $\begin{array}{l}\mathrm{Cl}_{\mathrm{ren}} \\
\left(\mathrm{l} / \mathrm{h} \cdot \mathrm{m}^{2}\right)\end{array}$ & $\begin{array}{l}\text { Urine } \\
(\%)\end{array}$ \\
\hline \multirow[t]{2}{*}{$\mathrm{U}$} & 1 & 12 & 62 & 496 & 36 & 24 & 46 & 2.0 & 8 \\
\hline & 2 & 12 & 33 & 333 & 29 & 36 & 33 & 4.0 & 12 \\
\hline \multirow[t]{3}{*}{$\mathrm{R}$} & 1 & 15 & 33 & 722 & 17 & 21 & 40 & 0.2 & 1 \\
\hline & 2 & 15 & 33 & 496 & 24 & 30 & 35 & - & - \\
\hline & 3 & 15 & 21 & 256 & 29 & 59 & 28 & 1.9 & 3 \\
\hline \multirow[t]{4}{*}{$\mathrm{P}$} & 1 & 10 & 44 & 370 & 28 & 27 & 63 & 2.4 & 9 \\
\hline & 2 & 10 & 53 & 563 & 23 & 18 & 40 & 2.2 & 12 \\
\hline & 3 & 10 & 55 & 347 & 38 & 29 & 65 & 0.7 & 2 \\
\hline & 4 & 10 & 53 & 265 & 48 & 38 & 63 & 4.0 & 11 \\
\hline \multirow[t]{3}{*}{$\mathrm{Me}$} & 1 & 12 & 39 & 548 & 21 & 22 & 55 & 2.3 & 11 \\
\hline & 2 & 13 & 79 & 722 & 37 & 18 & 74 & 2.8 & 16 \\
\hline & 3 & 12 & 70 & 691 & 29 & 17 & 67 & 3.8 & 22 \\
\hline \multirow[t]{2}{*}{ D } & 1 & 15 & 40 & 535 & 27 & 28 & 39 & 2.5 & 9 \\
\hline & 2 & 15 & 45 & 386 & 42 & 39 & 31 & 1.7 & 4 \\
\hline \multirow[t]{3}{*}{$\mathrm{Ma}$} & 1 & 13 & 51 & 732 & 22 & 18 & 54 & 0.2 & 1 \\
\hline & 2 & 12.5 & 44 & 343 & 39 & 36 & 58 & 0.3 & 1 \\
\hline & 3 & 10 & 40 & 360 & 27 & 28 & 58 & 0.4 & 1 \\
\hline \multirow[t]{5}{*}{$\mathrm{K}$} & 1 & 10 & 51 & 609 & 20 & 16 & 47 & 3.2 & 20 \\
\hline & 2 & 10 & 50 & 515 & 23 & 19 & 53 & 2.7 & 14 \\
\hline & 3 & 10 & 43 & 492 & 21 & 20 & 40 & 2.9 & 14 \\
\hline & 4 & 10 & 43 & 426 & 23 & 22 & 50 & 2.3 & 11 \\
\hline & 5 & 10 & 71 & 529 & 32 & 19 & 56 & 1.1 & 6 \\
\hline \multirow[t]{3}{*}{ Dr } & l & 15 & 26 & 622 & 10 & 16 & 38 & - & - \\
\hline & 2 & 15 & 26 & 722 & 13 & 21 & 34 & 1.3 & 3 \\
\hline & 3 & 15 & 31 & 321 & 36 & 47 & 27 & - & - \\
\hline \multirow[t]{2}{*}{$\mathrm{HJ}$} & 1 & 15 & 47 & 494 & 35 & 30 & 41 & 1.2 & 4 \\
\hline & 2 & 15 & 11 & 209 & 19 & 71 & 22 & 4.1 & 3 \\
\hline \multirow[t]{3}{*}{$\mathrm{L}$} & 1 & 15 & 37 & 695 & 20 & 22 & 42 & 3.3 & 15 \\
\hline & 2 & 15 & 26 & 362 & 27 & 43 & 30 & 2.9 & 7 \\
\hline & 3 & 15 & 31 & 658 & 17 & 23 & 35 & 1.1 & 5 \\
\hline \multirow[t]{2}{*}{ Mean $†$} & 1 & & 43 & 446 & $23.6 \pm 8.0$ & $22.4 \pm 4.9$ & 46.5 & 1.9 & 8.7 \\
\hline & 2 & & 40 & 364 & $27.6 \pm 9.2$ & $33.1 \pm 16.9$ & 41.0 & 2.4 & 8.0 \\
\hline
\end{tabular}

$* t_{1 / 2}=$ elimination half-life time; AUC $=$ area under the plasma concentration-time curve; $V_{\mathrm{d}}=$ distribution volume; $\mathrm{Cl}_{\text {tot }}=$ total body clearance; $\mathrm{MRT}=$ mean residence time; $\mathrm{Cl}_{\mathrm{ren}}=$ total renal clearance; urine $\%=$ percentage of administered dose excreted in the urine, collected till $4 \mathrm{~h}$ after injection.

$\dagger$ For the mean AUC values the MMC dose has been normalized to $10 \mathrm{mg} / \mathrm{m}^{2}$, assuming linear pharmacokinetics at this range.

As a result, AUCs were artificially lowered by up to $15 \%$. The $t_{1 / 2}$ is proportional to the ratio of the distribution volume and the clearance. For patient $\mathrm{R}$ (Table 1) both $\mathrm{Cl}_{\text {tot }}$ and $V_{\mathrm{d}}$ increased, each to varying extents, resulting in a net reduction of the $\iota_{1 / 2}$ during the three sequential courses (Fig. 2). All patients had normal liver and kidney functions and we were unable to explain the latter observations. Patient Me experienced an increase in $t_{1 / 2}$ (Fig. 3) when comparing the first with the later courses.

For the combination chemotherapy group a change in $t_{1 / 2}$ was also observed, as for patient $\mathrm{S}$ and patient Jo. These patients had normal kidney and liver functions. An overview of the variations in $V_{\mathrm{d}}$ and $\mathrm{Cl}_{\mathrm{tot}}$ that occurred within a patient during repeated administration can be seen in Figs 4 and 5 , respectively. The pharmacokinetic parameters of the first curve of each patient was set at $100 \%$. Pharmacokinetic parameters of second and sub- sequent curves are expressed relative to those of the first curve. Large interindividual variations between the various pharmacokinetic parameters can be observed. An increase in $\mathrm{Cl}_{\text {tot }}$ was observed when comparing the first and the second dose. The mean values were 22.4 and 33.1 (single agent) and 22.6 and 27.2 (combination) for the first and the second injection, respectively, as expressed in 1/ h. $\mathrm{m}^{2}$. This increase was significant for the single agent group $(P<0.05$, using a paired $l$-test $)$ and for the combination therapy group the difference was only significant at the $P=0.2 \mathrm{level}$. This increase may be explained by enhanced microsomal activity. This observation warrants further metabolism studies using hepatocytes. In the other parameters no significant differences between the mean values of first and sccond injection were observed. Although not statistically different the slight increase in the mean of $V_{\mathrm{d}}$, when comparing 
Table 2. Pharmacokinetic parameters of patients receiving combination chemotherapy

\begin{tabular}{|c|c|c|c|c|c|c|c|c|c|c|}
\hline Patient & $\begin{array}{l}\text { Curve } \\
\text { No. }\end{array}$ & $\begin{array}{l}\text { Dose } \\
\left(\mathrm{mg} / \mathrm{m}^{2}\right)\end{array}$ & $\begin{array}{l}t_{1 / 2} \\
(\min )\end{array}$ & $\begin{array}{l}\text { AUC } \\
(\mu \mathrm{g} \cdot \mathrm{h} / \mathrm{l})\end{array}$ & $\begin{array}{l}V_{\mathrm{d}} \\
\left(\mathrm{l} / \mathrm{m}^{2}\right)\end{array}$ & $\begin{array}{l}\mathrm{Cl}_{1,1} \\
\left(\mathrm{l} / \mathrm{h} \cdot \mathrm{m}^{2}\right)\end{array}$ & $\begin{array}{l}\text { MRT } \\
(\min )\end{array}$ & $\begin{array}{l}\mathrm{Cl}_{\text {ren }} \\
\left(\mathrm{l} / \mathrm{h} \cdot \mathrm{m}^{2}\right)\end{array}$ & $\begin{array}{l}\text { Urine } \\
(\%)\end{array}$ & $\begin{array}{l}\text { Other } \\
\text { agents* }\end{array}$ \\
\hline \multirow[t]{2}{*}{ M } & 1 & 6 & 43 & 476 & 13 & 13 & 38 & 1.9 & 15 & $\mathrm{~V}, \mathrm{~B}, \mathrm{P}$ \\
\hline & 2 & 6 & 42 & 368 & 16 & 16 & 39 & 1.4 & 8 & $\mathrm{~V}, \mathrm{~B}, \mathrm{P}$ \\
\hline \multirow[t]{2}{*}{ Mo } & 1 & 8 & 51 & 442 & 22 & 18 & 45 & 0.4 & 2 & A \\
\hline & 2 & 8 & 53 & 395 & 26 & 20 & 50 & 1.7 & 8 & A \\
\hline \multirow[t]{2}{*}{ J } & 1 & 10 & 35 & 271 & 31 & 37 & 47 & 7.0 & 19 & A \\
\hline & 2 & 10 & 22 & 273 & 19 & 37 & 35 & 7.2 & 20 & A \\
\hline \multirow[t]{6}{*}{ A } & 1 & 10 & 81 & 544 & 36 & 18 & 62 & 2.7 & 15 & A \\
\hline & 2 & 10 & 76 & 603 & 37 & 20 & 67 & 1.9 & 10 & A \\
\hline & 3 & 10 & 33 & 437 & 18 & 23 & 41 & 3.8 & 17 & A \\
\hline & 4 & 10 & 41 & 353 & 28 & 28 & 48 & - & - & A \\
\hline & 5 & 10 & 66 & 538 & 30 & 19 & 52 & 2.2 & 12 & A \\
\hline & 6 & 10 & 45 & 519 & 21 & 19 & 49 & 1.0 & 5 & A \\
\hline \multirow[t]{3}{*}{$\mathrm{S}$} & 1 & 10 & 55 & 421 & 31 & 24 & 56 & 3.2 & 13 & $\mathrm{~A}, 5-\mathrm{F}$ \\
\hline & 2 & 10 & 28 & 199 & 34 & 50 & 30 & 9.1 & 18 & $\mathrm{~A}, 5-\mathrm{F}$ \\
\hline & 3 & 10 & 86 & 312 & 60 & 29 & 73 & 3.4 & 12 & A,, $5-F$ \\
\hline \multirow[t]{2}{*}{ Jo } & 1 & 10 & 46 & 493 & 22 & 20 & 49 & 2.0 & 10 & VD \\
\hline & 2 & 10 & 97 & 358 & 65 & 28 & 61 & 2.7 & 10 & VD \\
\hline \multirow[t]{2}{*}{ Z } & 1 & 10 & 33 & 257 & 31 & 39 & 32 & 3.5 & 9 & A \\
\hline & 2 & 10 & 20 & 223 & 22 & 45 & 22 & - & - & A \\
\hline \multirow[t]{2}{*}{ DJ } & 1 & 10 & 61 & 611 & 24 & 16 & 60 & - & - & $\mathrm{A}, 5-\mathrm{F}$ \\
\hline & 2 & 10 & 87 & 744 & 28 & 13 & 69 & - & - & $A, 5-F$ \\
\hline \multirow[t]{2}{*}{ B } & 1 & 10 & 55 & 558 & 24 & 18 & 52 & - & - & $\mathrm{A}, 5-\mathrm{F}$ \\
\hline & 2 & 10 & 74 & 614 & 29 & 16 & 46 & - & - & $\mathrm{A}, 5-\mathrm{F}$ \\
\hline \multirow[t]{2}{*}{ Mean } & 1 & & 51 & $500^{\dagger}$ & $26.0 \pm 6.9$ & $22.6 \pm 19.3$ & 49.0 & 3.0 & 11.9 & \\
\hline & 2 & & 55 & $458^{\dagger}$ & $30.7 \pm 14.5$ & $27.2 \pm 13.6$ & 46.6 & 4.0 & 12.3 & \\
\hline
\end{tabular}

$* \mathrm{~A}=$ adriamycin $; \mathrm{V}=$ vincristine $; \mathrm{Vd}=$ vindesine $; \mathrm{B}=$ bleomycin $; \mathrm{P}=$ cisplatin $; 5-\mathrm{F}=5$-fluorouracil. $\dagger$ Standardized for a dose of $10 \mathrm{mg} / \mathrm{m}^{2}$.

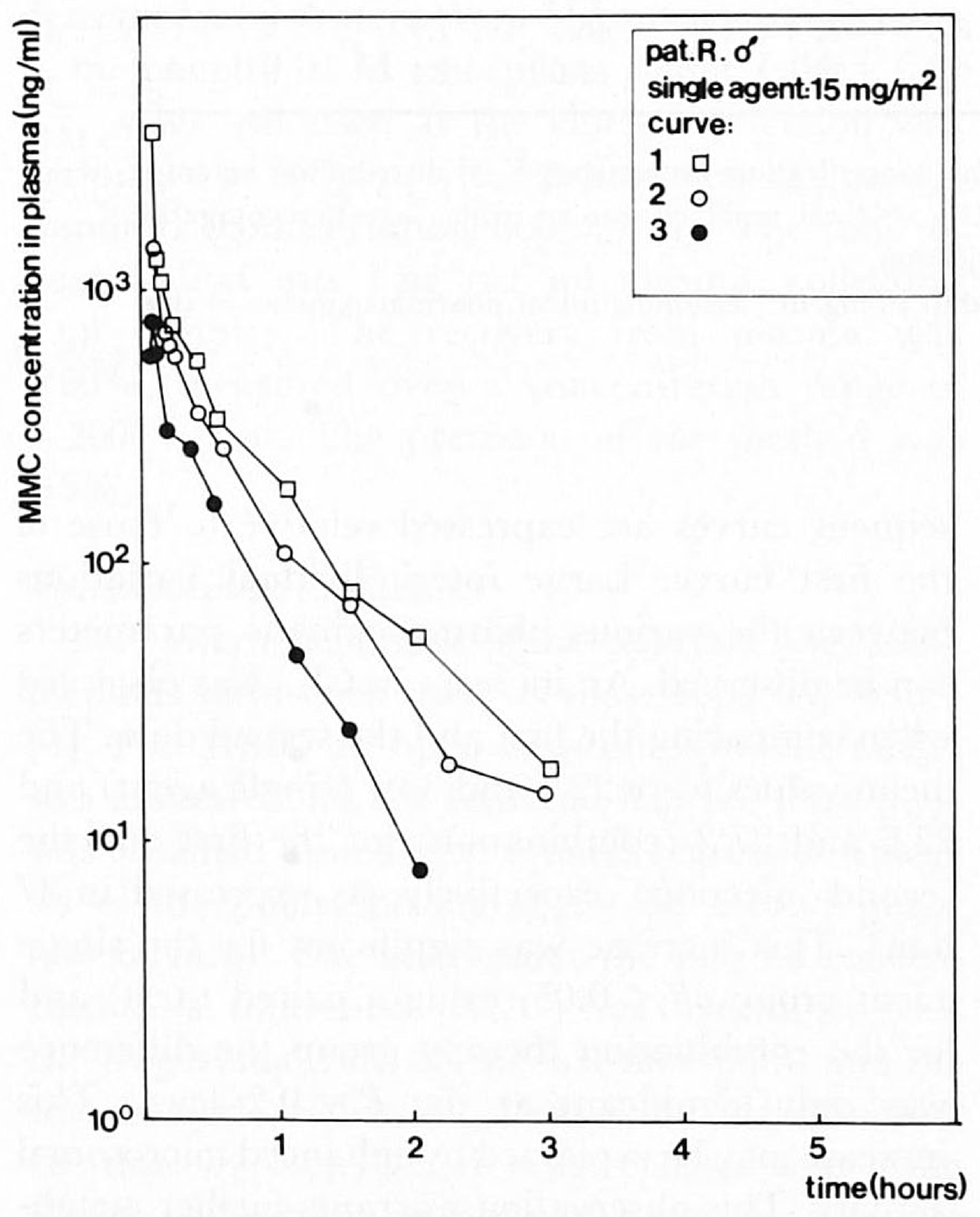

Fig. 2. Plasma concentration-time curve of MMC in patient $R$ who received $M M C$ as a single agent at a dose of $15 \mathrm{mg} / \mathrm{m}^{2}$. A decrease in the half-life of the elimination phase is observed: $t_{1 / 2}(1)=33 \mathrm{~min}, t_{1 / 2}$ $(2)=33 \mathrm{~min}, t_{1 / 2}(3)=21 \mathrm{~min}$. This patient had normal liver and kidney functions.

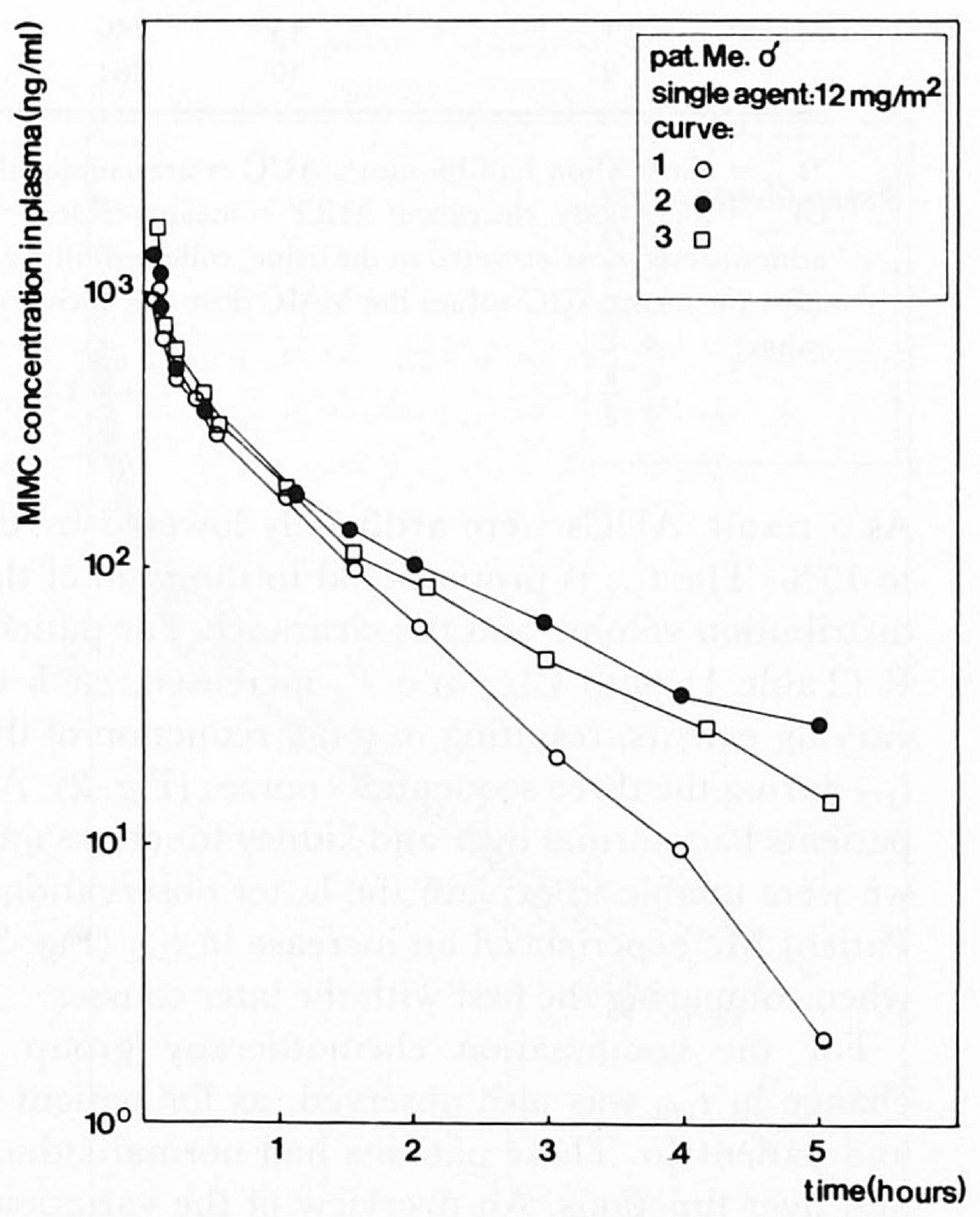

Fig. 3. Plasma concentration-time curve of MMC in patient Me (dose: $12 \mathrm{mg} / \mathrm{m}^{2}$ single agent). Kidney and liver functions were normal. An increase in $\mathrm{t}_{1 / 2}$ was seen in the second and third curve: $\mathrm{t}_{1 / 2}(1)=39 \mathrm{~min}$, $\mathrm{t}_{1 / 2}(2)=87 \mathrm{~min}$ and $\mathrm{t}_{1 / 2}(3)=70 \mathrm{~min}$. 


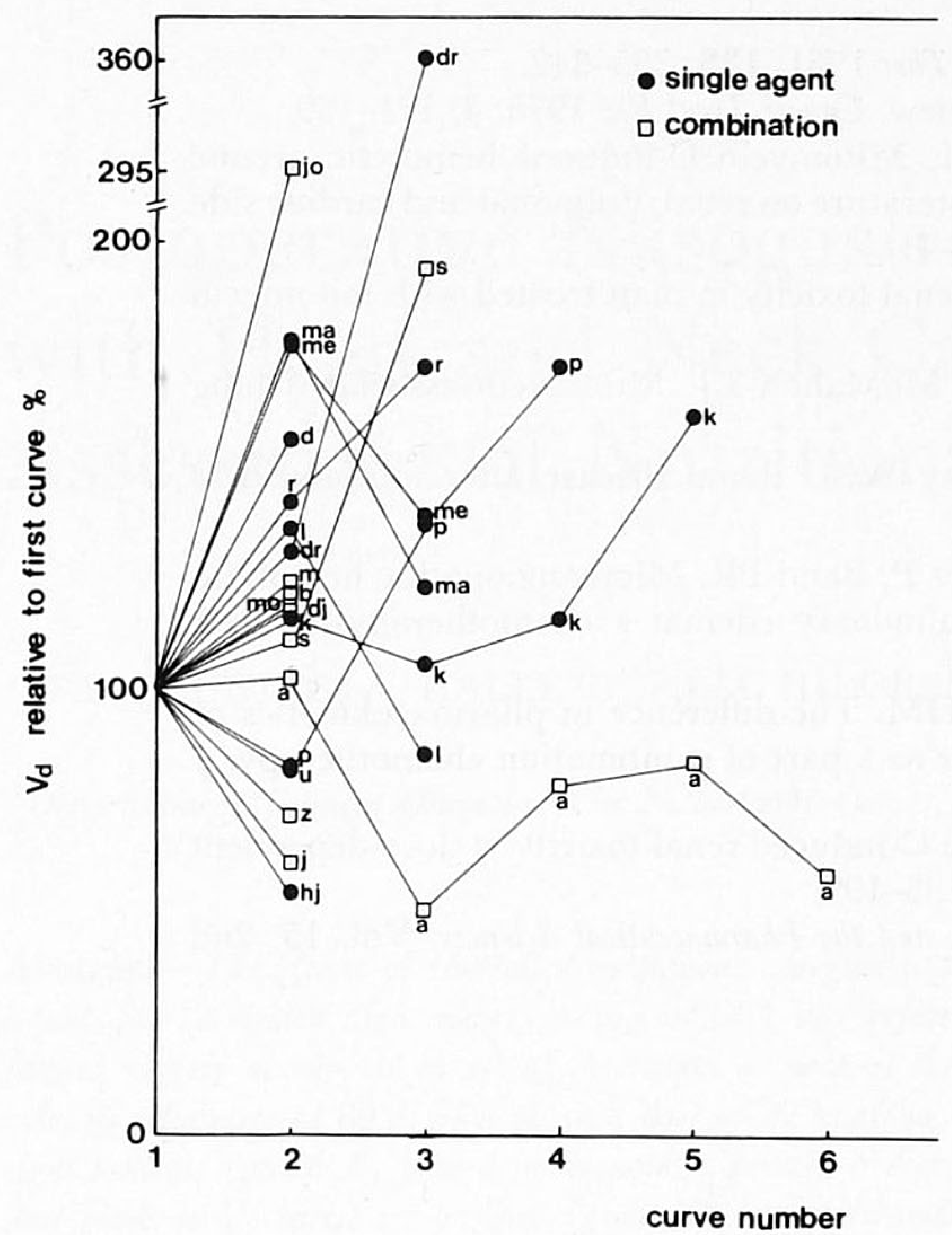

Fig. 4. Distribution volume $\mathrm{V}_{\text {" }}$ relative to first curve for all patients. Differences that occurred could not be related to liver or kidney toxicity.

the first and second injection, could be cxplaincd from a change in protein binding. The lower level of significance in the difference of the mean of $\mathrm{Cl}_{\text {(o) }}$ for the combination therapy group may be duc to the interference of other drugs. Although the primary aim of the presented study was not to evaluate toxicity in detail, the variations did not appear to correlate with clinical findings including

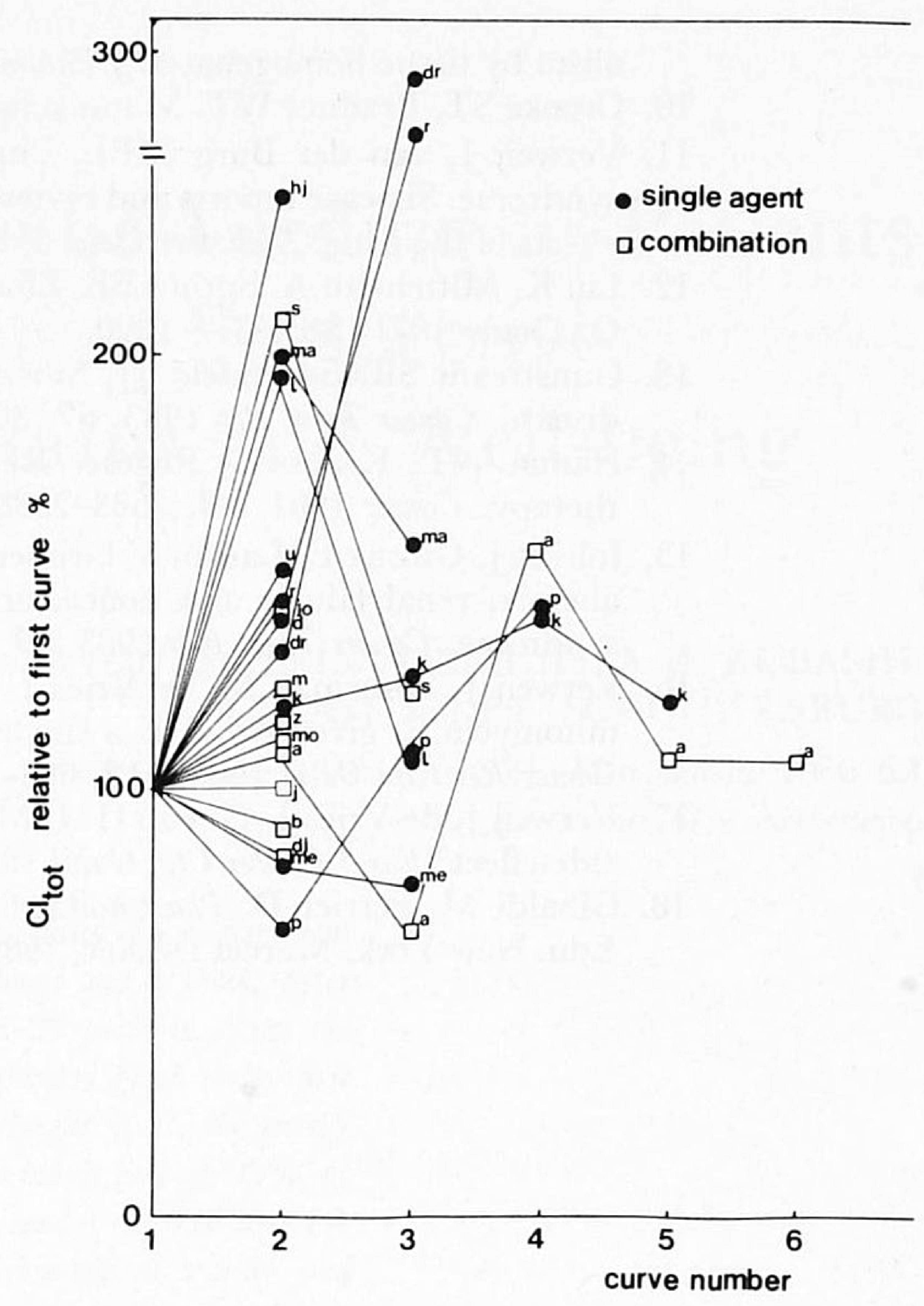

Fig. 5. Total body clearance $\left(\mathrm{Cl}_{t w 1}\right)$ relative to first curve. Patients with large differences between the first and subsequent curves showed no liver and/or kidney function disturbance.

blood cell count, renal function and liver function. In conclusion, the pharmacokinctic profiles of sequential courses of MMC failed to offer an cxplanation for the cumulative toxicity which tends to occur after repeated administration of MMC.

Acknowledgement-Helen Gall is gratefully acknowledged for collecting blood plasma samples of the patients.

\section{REFERENCES}

1. Pinedo HM, Chabner BA. Cancer Chemotherapy Annual. Amsterdam, Elsevier Excerpta Medica, 1979-1986.

2. Fujita H. Comparative studies on the blood level, tissue distribution, excretion and inactivation of anti-cancer drugs. Jap J Clin Oncol 1971, 12, 151-162.

3. Buice RG, Neill HB, Sidhu P, Gurley BJ. Pharmacokinetics of mitomycin C in non-oat cell carcinoma of the lung. Cancer Chemother Pharmacol 1984, 13, 1-4.

4. Den Hartigh J, McVie JG, van Oort WJ, Pinedo HM. Pharmacokinetics of mitomycin C in humans. Cancer Res 1983, 43, 5017-5021.

5. Van Hazel GA, Scott M, Rubin J. Pharmacokinetics of mitomycin C in patients receiving the drug alone or in combination. Cancer Treat Rep 1983, 67, 805-810.

6. Hu E, Howell SB. Pharmacokinetics of intraarterial mitomycin C in humans. Cancer Res 1983, 43, 4474-4477.

7. Schilcher RB, Young JD, Rathanatharathorn V, Karanes C, Baker LH. Clinical pharmacokinetics of high dose mitomycin C. Cancer Chemother Pharmacol 1984, 13, 186-198.

8. Den Hartigh J, van Oort WJ, Bocken MCYM, Pinedo HM. High performance liquid chromatography determination of the anti-tumor agent mitomycin $\mathrm{C}$ in human blood plasma. Anal Chim Acta 1981, 127, 47-53.

9. Schwartz HS, Philips FS. Pharmacology of mitomycin C. II. Renal excretion and metab- 
olism by tissue homogenates. J Pharmacol Exp Ther 1961, 133, 335-342.

10. Crooke ST, Bradner WT. Mitomycin C: a review. Cancer Treat Rev 1976, 3, 121-139.

11. Verweij J, van der Burg MEL, Pinedo HM. Mitomycin C-induced hemolytic uremic syndrome. Six case reports and review of the literature on renal, pulmonal and cardiac side effects of the drug. Radiother Oncol 1987, 8, 33-41.

12. Liu K, Mittelman A, Sproul EE, Elias EG. Renal toxicity in man treated with mitomycin C. Cancer 1971, 28, 1314-1320.

13. Gunstream SR, Seidenfeld JJ, Sibonya RE, McMahon LJ. Mitomycin-associated lung disease. Cancer Treat Rep 1983, 67, 301-304.

14. Hanna WT, Krauss S, Regeser RF, Murphy WM. Renal disease after mitomycin C therapy. Cancer 1981, 48, 2583-2588.

15. Jolivet J, Giroux L, Laurin S, Gruber J, Bettez P, Band PR. Microangiopathic hemolytic anemia, renal failure and noncardiogenic pulmonary edema: a chemotherapy-induced syndrome. Cancer Treat Rep 1983, 67, 429-434.

16. Verweij J, Stuurman M, de Vries J, Pinedo HM. The difference in pharmacokinetics of mitomycin $\mathrm{C}$, given either as a single agent or as a part of combination chemotherapy. $J$ Cancer Res Clin Oncol 1986, 112, 283-284.

17. Verweij J, de Vries J, Pinedo HM. Mitomycin C-induced renal toxicity, a dose-dependent side-effect? Eur J Cancer Clin Oncol 1987, 23, 195-199.

18. Gibaldi M, Perrier D. Pharmacokinetics. Drugs and the Pharmaceutical Sciences, Vol. 15, 2nd Edn. New York, Marcel Dekker, 1982. 